\title{
TRIC-B Mutations Causing Osteogenesis Imperfecta
}

\author{
Atsuhiko Ichimura $^{a, b}$ and Hiroshi Takeshima*,a \\ ${ }^{a}$ Graduate School of Pharmaceutical Sciences, Kyoto University; Kyoto 606-8501, Japan: and \\ ${ }^{b}$ Keihanshin Consortium for Fostering the Next Generation of Global Leaders in Research \\ (K-CONNEX), Kyoto University; Kyoto 606-8501, Japan. \\ Received July 29, 2016
}

\begin{abstract}
Trimeric intracellular cation (TRIC) channel subtypes, namely TRIC-A and TRIC-B, are expressed in the endoplasmic/sarcoplasmic reticulum and nuclear envelope, and likely function as monovalent cation channels in various cell types. Our studies using knockout mice so far suggest that TRIC subtypes support $\mathrm{Ca}^{2+}$ release from intracellular stores by mediating counter-cationic fluxes. Several genetic mutations within the TRIC-B locus were recently identified in autosomal recessive osteogenesis imperfecta (OI) patients. However, the molecular mechanism by which the mutations cause human disease is not fully addressed. We found that Tric-b-knockout mice exhibit poor bone ossification and thus serve as an OI-model animal. Studies on Tric- $b$-knockout bones and cultured cell lines derived from the patients currently reveal the main part of the pathophysiological mechanism involved in the TRIC-B-mutated OI form. This mini-review focuses on the essential role of TRIC-B channels in bone ossification.
\end{abstract} thesis

Key words bone development; endoplasmic reticulum; intracellular ionic channel; osteoblast; collagen syn-

\section{TRIMERIC INTRACELLULAR CATION (TRIC) CHANNELS}

Our previous immuno-proteomic screen in muscle membrane systems found novel transmembrane proteins with indirect roles in the $\mathrm{Ca}^{2+}$ handling of endo/sarcoplasmic reticulum (ER/SR), such as mitsugumin 29, mitsugumin 23 and junctophilins. ${ }^{1-3)}$ TRIC channel subtypes have also been identified in this molecular search. ${ }^{4}$ TRIC-A is preferentially expressed in excitable tissues, particularly in skeletal and cardiac muscle cells, and localized in the SR and nuclear envelope. Meanwhile, TRIC-B is ubiquitously distributed throughout tissues at moderate expression levels. In TRIC subtypes composed of $c a .300$ amino acid residues, three membrane-spanning segments are predicted, and the amino- and carboxyl-termini are assigned to the luminal and cytoplasmic sides, respectively. ${ }^{4}$ Moreover, TRIC-A preparations purified from both skeletal muscle and recombinant bacteria exhibit bullet-shaped homo-trimeric complexes, and form functional monovalent cation-selective channels in artificial lipid bilayers. ${ }^{4,5)}$ Skeletal and cardiac muscle SR contains the well-known decamethonium-sensitive $\mathrm{SR} \mathrm{K}^{+}$channel, ${ }^{6}$ ) which vaguely resembles TRIC subtypes in certain electrophysiological characteristics. However, TRIC subtypes are unlikely to form the authentic decamethonium-sensitive $\mathrm{K}^{+}$channel, because the recording frequency and gating features of the SR $\mathrm{K}^{+}$channel are not altered in SR preparations from Tric- $a$-knockout mice. ${ }^{7,8)}$

Knockout mice so far indicate that TRIC subtypes exert important roles during ER/SR $\mathrm{Ca}^{2+}$ release mediated by ryanodine (RyR) and inositol-trisphosphate receptors $\left(\mathrm{IP}_{3} \mathrm{R}\right)$. Double-knockout mice lacking both the subtypes die during early embryonic stages, and RyR-mediated $\mathrm{Ca}^{2+}$ release is weakened in the mutant cardiomyocytes. ${ }^{4)}$ In Tric-a-knockout mice, the mutant vascular smooth muscle shows poor RyRmediated $\mathrm{Ca}^{2+}$ sparks, $\left.{ }^{9}, 10\right)$ and the mutant skeletal muscle exhibits 'alternan' contractile responses which are likely generated due to compromised RyR-mediated $\mathrm{Ca}^{2+}$ release. ${ }^{11)}$ Moreover, Tric- $b$-knockout mice die immediately after birth due to respiratory failure, and the mutant alveolar epithelial cells exhibit insufficient handling of surfactant lipids, probably due to diminished $\mathrm{IP}_{3} \mathrm{R}$-mediated $\mathrm{Ca}^{2+}$ release. ${ }^{12)}$

Both RyRs and $\mathrm{IP}_{3} \mathrm{Rs}$ mediate $\mathrm{Ca}^{2+}$ release, rapidly activating and lasting for several milliseconds under physiological conditions. Such efficient $\mathrm{Ca}^{2+}$ release events would not be possible if only $\mathrm{Ca}^{2+}$ moved across the store membrane, because the initial efflux of the divalent cations would quickly generate negative membrane potential at the luminal side to inhibit subsequent $\mathrm{Ca}^{2+}$ release processes. Previous studies predicted that other ion species, such as $\mathrm{K}^{+}, \mathrm{Mg}^{2+}, \mathrm{Cl}^{-}$and/or $\mathrm{H}^{+}$, may provide counter-currents to suppress the membrane potential generation. ${ }^{13,14)}$ However, real channels/transporters generating the counter-currents had not yet been identified. Considering that TRIC subtypes are localized to $\mathrm{Ca}^{2+}$ stores as monovalent cation-selective channels, the observations from the knockout mice suggest that TRIC channels could provide certain aspects of the counter-ion movement during ER/SR $\mathrm{Ca}^{2+}$ release (Fig. 1A). This hypothesis is also supported by data from the fluorometric membrane potential monitoring of SR vesicles from skeletal muscle. ${ }^{4)} \mathrm{Ca}^{2+}$-loaded Tric- $a$-knockout vesicles under ATP-containing conditions displayed a slightly negative potential compared to wild-type vesicles. This negative potential was increased by $\mathrm{Ca}^{2+}$ leakage triggered by a $\mathrm{Ca}^{2+}$-pump inhibitor, while application of a $\mathrm{K}^{+}$ionophore eliminates the difference in membrane potential between the knockout and wild-type vesicles. Therefore, Tric$a$ deficiency seems to alter membrane potential due to reduced $\mathrm{K}^{+}$permeability in the muscle SR.

\section{OSTEOGENESIS IMPERFECTA (OI)}

OI is a group of divergent hereditary diseases characterized by low bone mass, and leads to increased bone fragility. The 
Table 1. Classified and Unclassified OI Forms

\begin{tabular}{|c|c|c|c|c|}
\hline OI type & Defective gene & Defective protein & Primary defect in osteoblast & OI phenotype \\
\hline \multicolumn{5}{|l|}{ Dominant inheritance: } \\
\hline \multicolumn{5}{|l|}{ Classical silllence type } \\
\hline I & COL1A1 (null) & $\alpha 1$ collagen & Collagen synthesis & Mild \\
\hline II & COL1A1/COL1A2 & $\alpha 1 / \alpha 2$ collagen & Collagen structure & Lethal \\
\hline III & COL1A1/COL1A2 & $\alpha 1 / \alpha 2$ collagen & Collagen structure & Progressive \\
\hline IV & COL1A1/COL1A2 & $\alpha 1 / \alpha 2$ collagen & Collagen structure & Moderate \\
\hline \multicolumn{5}{|l|}{ COL1-mutation negative } \\
\hline $\mathrm{V}$ & IFITM5 & $\begin{array}{c}\text { Interferon induced } \\
\text { transmembrane protein } 5\end{array}$ & $\begin{array}{c}\text { Interaction with prolyl } \\
\text { isomerase FKBP11? }\end{array}$ & Mild to moderate \\
\hline \multicolumn{5}{|l|}{ Recessive inheritance: } \\
\hline \multicolumn{5}{|l|}{$\overline{\text { Mineralization defect }}$} \\
\hline VI & SERPINF1 & Pigment epithelium-derived factor & Phospholipase A2 signaling? & Moderate to severe \\
\hline \multicolumn{5}{|l|}{ Hydroxylation defect } \\
\hline VII & CRTAP & $\begin{array}{l}\text { Prolyl-3-hydroxylase } \\
\text { family member } 5\end{array}$ & Collagen hydroxylation & Severe to lethal \\
\hline VIII & LEPRE1 & Prolyl-3-hydroxylase-1 & Collagen hydroxylation & Severe to lethal \\
\hline IX & PPIB & Peptidyl-prolyl isomerase B & Collagen hydroxylation & Moderate to lethal \\
\hline \multicolumn{5}{|l|}{ Chaperone defect } \\
\hline $\mathrm{X}$ & SERPINH1 & Chaperone Hsp47 & Collagen folding & Severe to lethal \\
\hline $\mathrm{XI}$ & FKBP10 & FK506-binding protein 10 & $\begin{array}{l}\text { Collagen telopeptide } \\
\text { hydroxylation }\end{array}$ & Variable \\
\hline \multicolumn{5}{|l|}{ Propeptide-cleavage defect } \\
\hline XII & BMP1 & Metalloproteinase BMP1 & BMP2/4 activation & Severe \\
\hline \multicolumn{5}{|l|}{ Unclassified form } \\
\hline Transcription factor defect & SP7/OSX & Zinc finger transcription factor SP7 & Cellular maturation & Moderate \\
\hline Cation channel defect & TRIC-B/TMEM38B & Intracellular TRIC-B channel & ER ionic homeostasis & Moderate \\
\hline Wnt signaling defect & WNT1 & Proto-oncogene protein Wnt-1 & Cellular maturation? & Progressive \\
\hline ER stress transducer defect & CREBL1 & bZIP transcription factor OASIS & COL1A1 transcription? & Severe \\
\hline
\end{tabular}

incidence of OI is approximately 1 in 20000 births, and a vast majority of the cases are due to defects in type I collagen. Several varied manifestations are often observed in OI cases, such as persistently blue sclera, shortened and bowed limbs, and brittle opalescent teeth, demonstrating the involvement of multiple OI-causing genes. ${ }^{15)}$ Based on clinical characteristics, including disease severity, Sillence et al. defined an authentic classification of OI subtypes in 1979; OI type I is the mild and major form exhibiting blue sclera, type II is the perinatal lethal form characterized by crumpled and beaded bones, type III is the progressive form maintaining normal sclera, and type IV contains moderate to severe cases with normal sclera. ${ }^{16)}$ However, with an increase in newly identified causative genes, OI is now shown to be a highly divergent disease with different inheritance patterns, variable severities and multifaceted clinical conditions, and thus Sillence's classification has been repeatedly revised. In parallel, genetics-based OI classifications were proposed, ${ }^{17,18)}$ but it became impossible to maintain pathological correlations between Sillence's types and OI-responsible genes, as shown in Table 1. To avoid confusing implications in clinical practice, in 2009 the International Society of Skeletal Dysplasias released a standard classification, in which Sillence's typing is maintained as the prototypical form. In this new typing, OI cases are separated into five groups, and causative genes are simply listed in each group. ${ }^{19,20)}$

In developing bones, active osteoblasts extensively produce bone matrix and matrix vesicles to facilitate ossification. Type I collagen is the main protein component of bone matrix, and consists of $\alpha 1$ and $\alpha 2$ chains, encoded by COL1A1 and COL1A2, respectively. Mutations in both genes affect the structure and/or amount of bone matrix, leading to bone abnormalities with subclinical to lethal phenotypes. COL1A1 and COL1A2 mutations in OI cases often exert dominant negative effects, because mutant $\alpha$ chains assemble with normal chains during collagen biosynthesis and thus possibly impair the quality of bone matrix. The functional maturation of collagen requires multiple post-translational modification and folding processes, and various mutations in processing enzymes (CRTAP, LEPRE1 and PPIB) and chaperone genes (FKBP10,

\section{Biography}

Hiroshi Takeshima obtained his B.S. at Tokyo University of Agriculture and Technology in 1983 and Ph.D. at Kyoto University in 1989, then received appointments at several institutes as junior and senior faculty member for academic training. During this period, he focused on identifying and characterizing new muscle membrane components, including ryanodine receptors, junctophilins and mitsugumin 53. After his appointment as Professor at Kurume University and Tohoku University, he moved to the Graduate School of Pharmaceutical Sciences at Kyoto University in 2006, and has been studying TRIC channels and other new membrane proteins. 
A

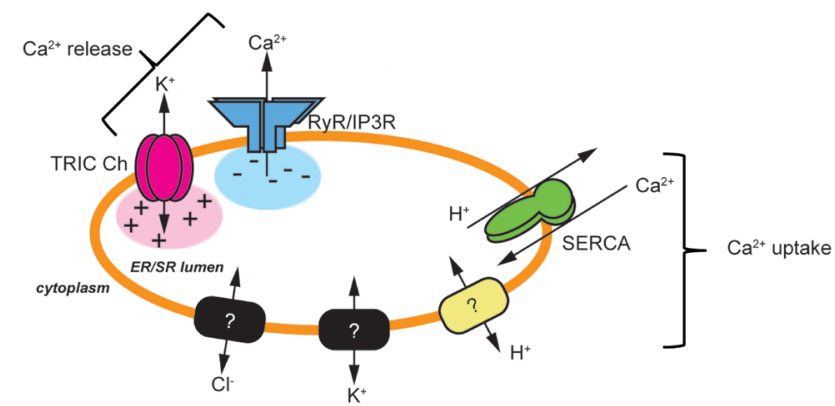

B

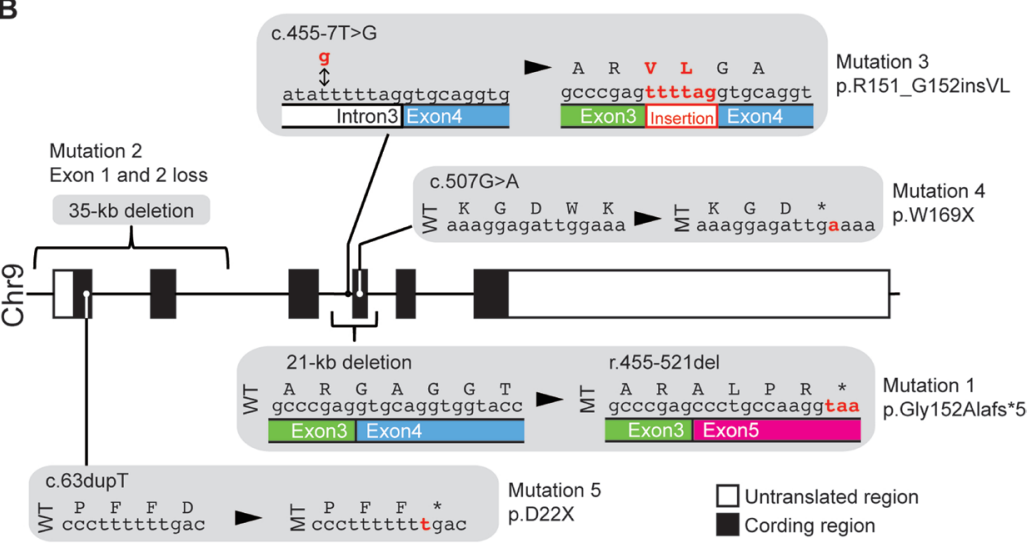

Fig. 1. Proposed TRIC Function and OI Mutations at TRIC-B Locus

(A) Schematic diagram of TRIC channels in intracellular $\mathrm{Ca}^{2+}$ stores. Physiological $\mathrm{Ca}^{2+}$ release mediated by RyRs and $\mathrm{IP}_{3} \mathrm{Rs}$ probably requires counter-ion movements to stabilize ER/SR potential. Previous studies predicted $\mathrm{H}^{+}, \mathrm{K}^{+}$and $\mathrm{Cl}^{-}$channels in the ER/SR, but their molecular identities and biological functions are unknown. (B) Schematic diagram of OI mutations in the human TRIC-B/TMEM38 gene on Chromosome 9. The OI mutations 1,2,3, 4 and 5 (ref. 21-25) are shown.

SERPINHI and SERPINF1) have been also identified in OI pedigrees. Moreover, OI-causing mutations are found in several collagen-unrelated genes, such as $S P 7$ (osteoblast-specific transcription factor Osterix), WNT1 (signaling peptide WNT1) and IFITM5 (osteoblast-specific transmembrane protein). Full function of these genes is probably important for developmental maturation in osteoblasts.

Recently, homozygous mutations in the TRIC-B (also referred to as TMEM38B) locus has been identified in OI pedigrees from different races. As shown in Fig. 1B, the Arabic mutant locus encodes a truncated TRIC-B protein lacking the carboxy-terminal half (mutation 1), ${ }^{21,22}$ whereas the $5^{\prime}$-terminal region encompassing exons 1 and 2 is deleted in the Albanian mutant locus (mutation 2). ${ }^{23)}$ Furthermore, three additional loci were recently reported in Chinese and American OI patients ${ }^{24,25)}$; a mutation disrupting the acceptor splice site of intron 3 (mutation 3), and mutations in exon 4 (mutation 4) and exon 1 (mutation 5). These critical OI-causing mutations presumably result in functionally-defective TRIC-B channels. Based on the phenotypes of 22 cases reported to date, ${ }^{21-24)} \mathrm{OI}$ patients bearing the $T R I C-B$ mutations develop moderately severe OI, and have various fracture frequency, mildly or moderately short stature, gray to blue sclera and no tooth defect. However, the pathophysiological mechanism remains to be addressed in these OI patients.

\section{OI-LIKE PHENOTYPE IN Tric- $b$-KNOCKOUT MICE}

Ablation of the Tric- $b$ gene produces an OI-like bone phenotype in mouse. ${ }^{26)}$ Although Tric- $b$-knockout mice are slightly smaller in whole body size than wild-type controls, ${ }^{12)}$ their overall skeletal formation is macroscopically normal.
A
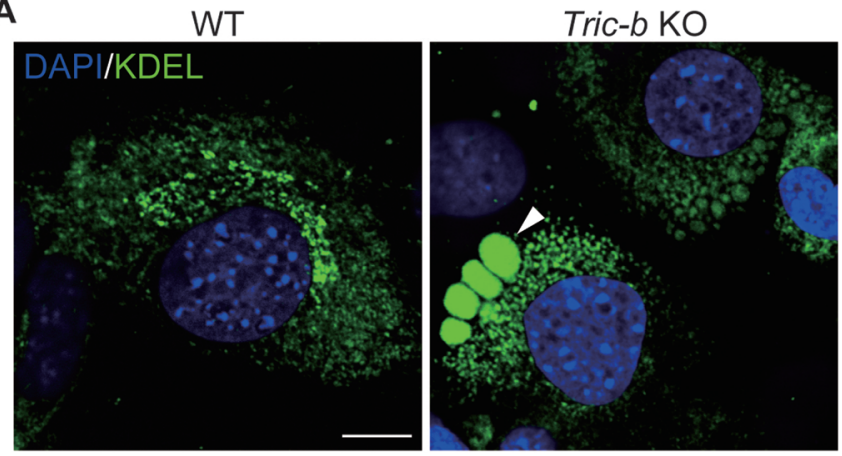

B Osteoblast

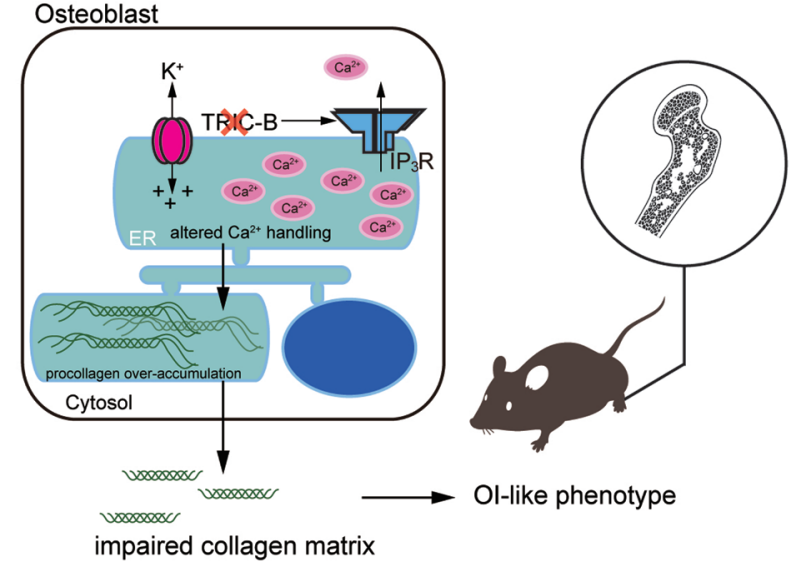

Fig. 2. OI-Like Phenotype in Tric-b-Knockout Mice

(A) Immunocytochemical detection of procollagen in cultured osteoblasts. Procollagen-positive green signals formed meshwork structures in most wild-type osteoblasts (left panel), while enlarged deposits packed with procollagen $(>5 \mu \mathrm{m}$ in diameter) were frequently observed in Tric- $b$-knockout osteoblasts. Scale bar, $10 \mu \mathrm{m}$. (B) Schematic diagram representing the pathophysiology of Tric- $b$-knockout OI-like phenotype. 
However, in the knockout mice, bone mineralization was remarkably poor; both calcium and collagen depositions were obviously decreased in major bones including the skull, ribs, and femur. Based on impaired ossification in both endochondral and intramembranous bones, ${ }^{27)}$ it was hypothesized that inactivated osteoblasts and/or hyper-activated osteoclasts may be responsible for the OI-like phenotype. However, histochemical and gene expression analyses suggested that the knockout femoral bones regularly maintain bone-related cells, including osteoblasts and osteoclasts.

In electron-microscopic analysis of bone tissues, dilated rough ER elements, regressing Golgi bodies and sparse secretory vesicles were detected in Tric- $b$-knockout osteoblasts. In biochemical experiments using primary cultured osteoblasts, Tric- $b$ deficiency significantly reduced the deposition of both extracellular mineral and collagen, but increased intracellular procollagen content. The excess procollagen fibers were immunocytochemically detected as dense cytoplasmic deposits within cultured Tric- $b$-knockout osteoblasts (Fig. 2A), and these deposits were also decorated with an antibody to the ER marker KDEL. These observations in primary cultured osteoblasts were fully consistent with the reduction of both collagen matrix and mineral depositions detected in major bones from Tric- $b$-knockout mice. Tric- $b$ deficiency probably induces the ER retention of procollagen, leading to severe ER dilation, and thus inhibits collagen production in osteoblasts. In the same manner as the major human OI forms, an insufficient collagen matrix seems to be the causal factor of the OI-like phenotype in the knockout mice.

TRIC subtypes likely form monovalent cation channels implicated in the maintenance of $\mathrm{Ca}^{2+}$-store function. In fluorometric $\mathrm{Ca}^{2+}$ imaging, cultured Tric- $b$-knockout osteoblasts exhibited impaired $\mathrm{IP}_{3} \mathrm{R}$-mediated $\mathrm{Ca}^{2+}$ release and store $\mathrm{Ca}^{2+}$ overloading. Additionally, the transfection of Tric- $b$ cDNA rescued not only the altered store $\mathrm{Ca}^{2+}$ handling, but also ER dilation and collagen production in the cultured knockout cells. In general terms, ER dilation is an ultrastructural sign of ER stress, and store $\mathrm{Ca}^{2+}$ overloading often aggravates ER stress. Gene expression profiling suggested that the unfolded protein response (UPR) and ER-associated degradation (ERAD) are activated in Tric- $b$-knockout osteoblasts. It is likely that the excess accumulation of procollagen induces both ER stress and dilation.

Our experiments could not detect any abnormal features in Tric- $b$-knockout osteoclasts. Osteoclasts exhibited regular ultrastructures in Tric- $b$-knockout mice, and primary cultured osteoclasts derived from the knockout mice preserved normal cell growth, maturation and bone resorption. Therefore, facilitated bone resorption was unlikely to contribute to the OI-like phenotype. Taken together, TRIC-B channels seem to have an essential role in the mass production of collagen in osteoblasts, and thereby Tric- $b$ deficiency causes impaired collagen production and inhibits efficient bone mineralization (Fig. 2B).

\section{ABNORMAL FEATURES IN CULTURED CELL LINES FROM TRIC-B-MUTATED OI PATIENTS}

Cabral et al. currently reported altered features in cultured fibroblast and osteoblast cell lines derived from TRIC-B-mutated OI patients. ${ }^{25}$ Their biochemical and immunochemical experiments indicated that the TRIC-B mutations, correspond- ing to mutation 1 and mutation 5 in Fig. $1 \mathrm{~B}$, results in functional null alleles. The human OI cells exhibited decreased synthesis, secretion and deposition of type I collagen. In addition, the assembly and lysyl-hydroxylation of procollagen fibers were impaired in the OI cells, and thus matrix collagen exhibited an unstable conformation. Moreover, the OI cells displayed enhanced ER stress; UPR-related proteins, such as activating transcription factor 4 (ATF4) and Bip/GRP78, were significantly up-regulated. These observations are consistent with the results from Tric- $b$-knockout mice.

In fluorometric $\mathrm{Ca}^{2+}$ measurements, the human OI cells showed impaired $\mathrm{IP}_{3} \mathrm{R}$-mediated $\mathrm{Ca}^{2+}$ release. However, in contrast to the observations in Tric- $b$-knockout osteoblasts, the resting cytosolic $\mathrm{Ca}^{2+}$ level was reduced and a response indicative of store $\mathrm{Ca}^{2+}$ overloading was not detected in the OI cells. The reason for this apparent discrepancy between the human OI cells and mouse Tric- $b$-knockout osteoblasts is unknown. However, based on the data from the OI cells, Cabral et al. concluded that TRIC-B mutations cause OI by dysregulation of $\mathrm{ER} \mathrm{Ca}^{2+}$ homeostasis, impacting multiple collagenspecific chaperones and modifying enzymes in osteoblasts. ${ }^{25}$ )

\section{FUTURE PERSPECTIVE}

Current studies using knockout mice and human OI cells uncovered the essential role of TRIC-B in osteoblastic collagen production. TRIC-B mutations found in OI patients seem to result in functional null alleles (Fig. 1B). As in the knockout mice, an insufficient collagen matrix is reasonably predicted in patients bearing TRIC-B mutations. From a phenotypical point of view, it is worth mentioning the difference in lung function between the knockout mice and human OI patients. Tric- $b$-knockout mice exhibit birth asphyxia due to poor surfactant production in alveolar epithelial cells, ${ }^{12)}$ while no respiratory failure was reported in the OI patients. ${ }^{21-24)}$ It is unclear why this phenotypical difference is observed. In mouse alveolar cells, Tric- $a$ expression is very low, and TRIC-B channels might predominantly mediate counter-ionic currents during ER $\mathrm{Ca}^{2+}$ release. ${ }^{12)}$ In contrast, compensatory activation of other channels/transporters, including TRIC-A channels, could preserve surfactant production in human alveolar cells. For better understanding the molecular basis of counter-ionic flows in non-excitable cells, it may be important to compare gene expression between mouse and human alveolar epithelial cells and to profile candidate channels/transporters in the ER.

In a few OI patients bearing TRIC-B mutations, bisphosphonate treatments seemed to effectively increase bone mineral density (BMD) and to reduce fracture incidence. ${ }^{24)}$ However, in order to establish the clinical benefit, the efficacy of such medications needs to be objectively and statistically evaluated in model experimental systems. Tric- $b$-knockout mice probably provide a useful model system towards the development of medical treatments for human patients. As explained above, the impaired folding and excess retention of procollagen in the ER are recognized as an essential cause of the TRIC-Bmutated OI form. Although the detailed mechanism is still unclear, altered $\mathrm{Ca}^{2+}$ handling is suspected of contributing to the procollagen retention. A majority of ER luminal enzymes, including chaperones, are functioning in a $\mathrm{Ca}^{2+}$-dependent manner, and may be inactivated under $\mathrm{Ca}^{2+}$-overloaded 
conditions. Therefore, disturbed procollagen processing and folding may lead to aggravated ER stress in TRIC-B-mutated osteoblasts. To facilitate protein-folding functions in the ER, chemical chaperones, including tauroursodeoxycholic acid and 4-phenylbutyrate, ${ }^{28,29)}$ have been developed in recent years. Such chemical chaperones could be candidates for medication to ameliorate OI conditions.

Acknowledgments This work was supported in part by the MEXT/JSPS (KAKENHI 15H04676, 15H05652) and the Keihanshin Consortium for Fostering the Next Generation of Global Leaders in Research (K-CONNEX).

Conflict of Interest The authors declare no conflict of interest.

\section{REFERENCES}

1) Takeshima H, Komazaki S, Nishi M, Iino M, Kangawa K. Junctophilins: a novel family of junctional membrane complex proteins. Mol. Cell, 6, 11-22 (2000).

2) Takeshima $\mathrm{H}$, Shimuta M, Komazaki S, Ohmi K, Nishi M, Iino M, Miyata A, Kangawa K. Mitsugumin 29, a novel synaptophysin family member from the triad junction in skeletal muscle. Biochem. J., 331, 317-322 (1998).

3) Venturi E, Mio K, Nishi M, Ogura T, Moriya T, Pitt SJ, Okuda K, Kakizawa S, Sitsapesan R, Sato C, Takeshima H. Mitsugumin 23 forms a massive bowl-shaped assembly and cation-conducting channel. Biochemistry, 50, 2623-2632 (2011).

4) Yazawa M, Ferrante C, Feng J, Mio K, Ogura T, Zhang M, Lin PH, Pan Z, Komazaki S, Kato K, Nishi M, Zhao X, Weisleder N, Sato C, Ma J, Takeshima H. TRIC channels are essential for $\mathrm{Ca}^{2+}$ handling in intracellular stores. Nature, 448, 78-82 (2007).

5) Pitt SJ, Park KH, Nishi M, Urashima T, Aoki S, Yamazaki D, Ma J, Takeshima H, Sitsapesan R. Charade of the SR K ${ }^{+}$-channel: two ion-channels, TRIC-A and TRIC-B, masquerade as a single $\mathrm{K}^{+}$channel. Biophys. J., 99, 417-426 (2010).

6) Coronado R, Miller C. Decamethonium and hexamethonium block $\mathrm{K}^{+}$channels of sarcoplasmic reticulum. Nature, 288, 495-497 (1980).

7) Matyjaszkiewicz A, Venturi E, O'Brien F, Iida T, Nishi M, Takeshima $\mathrm{H}$, Tsaneva-Atanasova K, Sitsapesan R. Subconductance gating and voltage sensitivity of sarcoplasmic reticulum $\mathrm{K}(+)$ channels: a modeling approach. Biophys. J., 109, 265-276 (2015).

8) Venturi E, Matyjaszkiewicz A, Pitt SJ, Tsaneva-Atanasova K, Nishi M, Yamazaki D, Takeshima H, Sitsapesan R. TRIC-B channels display labile gating: evidence from the TRIC-A knockout mouse model. Pflugers Archiv: European Journal of Physiology, 465, 1135-1148 (2013)

9) Tao S, Yamazaki D, Komazaki S, Zhao C, Iida T, Kakizawa S, Imaizumi Y, Takeshima H. Facilitated hyperpolarization signaling in vascular smooth muscle-overexpressing TRIC-A channels. $J$. Biol. Chem., 288, 15581-15589 (2013).

10) Yamazaki D, Tabara Y, Kita S, Hanada H, Komazaki S, Naitou D, Mishima A, Nishi M, Yamamura H, Yamamoto S, Kakizawa S, Miyachi H, Yamamoto S, Miyata T, Kawano Y, Kamide K, Ogihara T, Hata A, Umemura S, Soma M, Takahashi N, Imaizumi Y, Miki T, Iwamoto T, Takeshima H. TRIC-A channels in vascular smooth muscle contribute to blood pressure maintenance. Cell Metab., 14, 231-241 (2011).

11) Zhao X, Yamazaki D, Park KH, Komazaki S, Tjondrokoesoemo A, Nishi M, Lin P, Hirata Y, Brotto M, Takeshima H, Ma J. $\mathrm{Ca}^{2+}$ overload and sarcoplasmic reticulum instability in TRIC-A null skeletal muscle. J. Biol. Chem., 285, 37370-37376 (2010).

12) Yamazaki D, Komazaki S, Nakanishi H, Mishima A, Nishi M,
Yazawa M, Yamazaki T, Taguchi R, Takeshima H. Essential role of the TRIC-B channel in $\mathrm{Ca}^{2+}$ handling of alveolar epithelial cells and in perinatal lung maturation. Development, 136, 2355-2361 (2009).

13) Somlyo AV, Gonzalez-Serratos HG, Shuman H, McClellan G, Somlyo AP. Calcium release and ionic changes in the sarcoplasmic reticulum of tetanized muscle: an electron-probe study. J. Cell Biol., 90, 577-594 (1981)

14) Somlyo AV, McClellan G, Gonzalez-Serratos H, Somlyo AP. Electron probe X-ray microanalysis of post-tetanic $\mathrm{Ca}^{2+}$ and $\mathrm{Mg}^{2+}$ movements across the sarcoplasmic reticulum in situ. J. Biol. Chem., 260, 6801-6807 (1985).

15) Byers PH, Pyott SM. Recessively inherited forms of osteogenesis imperfecta. Annu. Rev. Genet., 46, 475-497 (2012).

16) Sillence DO, Senn A, Danks DM. Genetic heterogeneity in osteogenesis imperfecta. J. Med. Genet., 16, 101-116 (1979).

17) Forlino A, Marini JC. Osteogenesis imperfecta. Lancet, 387, $1657-$ $1671(2016)$.

18) Valadares ER, Carneiro TB, Santos PM, Oliveira AC, Zabel B. What is new in genetics and osteogenesis imperfecta classification? J. Pediatr., 90, 536-541 (2014).

19) Marini JC, Blissett AR. New genes in bone development: what's new in osteogenesis imperfecta. J. Clin. Endocrinol. Metab., 98, 3095-3103 (2013)

20) Marini JC, Reich A, Smith SM. Osteogenesis imperfecta due to mutations in non-collagenous genes: lessons in the biology of bone formation. Curr. Opin. Pediatr., 26, 500-507 (2014).

21) Shaheen R, Alazami AM, Alshammari MJ, Faqeih E, Alhashmi N, Mousa N, Alsinani A, Ansari S, Alzahrani F, Al-Owain M, Alzayed ZS, Alkuraya FS. Study of autosomal recessive osteogenesis imperfecta in Arabia reveals a novel locus defined by TMEM38B mutation. J. Med. Genet., 49, 630-635 (2012).

22) Volodarsky M, Markus B, Cohen I, Staretz-Chacham O, Flusser $\mathrm{H}$, Landau D, Shelef I, Langer Y, Birk OS. A deletion mutation in TMEM38B associated with autosomal recessive osteogenesis imperfecta. Hum. Mutat., 34, 582-586 (2013).

23) Rubinato E, Morgan A, D'Eustacchio A, Pecile V, Gortani G, Gasparini P, Faletra F. A novel deletion mutation involving TMEM38B in a patient with autosomal recessive osteogenesis imperfecta. Gene, 545, 290-292 (2014).

24) Lv F, Xu XJ, Wang JY, Liu Y, Asan, Wang JW, Song LJ, Song YW, Jiang Y, Wang O, Xia WB, Xing XP, Li M. Two novel mutations in TMEM38B result in rare autosomal recessive osteogenesis imperfecta. J. Hum. Genet., 61, 539-545 (2016).

25) Cabral WA, Ishikawa M, Garten M, Makareeva EN, Sargent BM, Weis M, Barnes AM, Webb EA, Shaw NJ, Ala-Kokko L, Lacbawan FL, Hogler W, Leikin S, Blank PS, Zimmerberg J, Eyre DR, Yamada Y, Marini JC. Absence of the ER cation channel TMEM38B/ TRIC-B disrupts intracellular calcium homeostasis and dysregulates collagen synthesis in recessive osteogenesis imperfecta. PLOS Genet., 12, e1006156 (2016).

26) Zhao C, Ichimura A, Qian $N$, Iida $T$, Yamazaki D, Noma N, Asagiri M, Yamamoto K, Komazaki S, Sato C, Aoyama F, Sawaguchi A, Kakizawa S, Nishi M, Takeshima H. Mice lacking the intracellular cation channel TRIC-B have compromised collagen production and impaired bone mineralization. Sci. Signal., 9, ra49 (2016).

27) Berendsen $\mathrm{AD}$, Olsen BR. Bone development. Bone, 80, 14-18 (2015)

28) Cao SS, Zimmermann EM, Chuang BM, Song B, Nwokoye A, Wilkinson JE, Eaton KA, Kaufman RJ. The unfolded protein response and chemical chaperones reduce protein misfolding and colitis in mice. Gastroenterology, 144, 989-1000.e6 (2013).

29) Murray LS, Lu Y, Taggart A, Van Regemorter N, Vilain C, Abramowicz M, Kadler KE, Van Agtmael T. Chemical chaperone treatment reduces intracellular accumulation of mutant collagen IV and ameliorates the cellular phenotype of a COL4A2 mutation that causes haemorrhagic stroke. Hum. Mol. Genet., 23, 283-292 (2014). 